\title{
Tissue injuries after single-port and multiport laparoscopic gynecologic surgeries: A prospective multicenter study
}

\author{
KYEONG A SO ${ }^{1}$, JAE KWAN LEE ${ }^{2}$, JAE YUN SONG ${ }^{3}$, JAE WON KIM ${ }^{4}$, NAK WOO LEE ${ }^{4}, \mathrm{KYUNG}^{-D O} \mathrm{KI}^{5}$, \\ JONG-MIN LEE ${ }^{5}$, YONG JUNG SONG ${ }^{6}$, YONG JIN NA ${ }^{6}$, CHUN HOE KU ${ }^{7}$, JIN WOO SHIN ${ }^{7}$, \\ CHUL JUNG KIM ${ }^{8}$ and UN SUK JUNG ${ }^{9}$
}

${ }^{1}$ Department of Obstetrics and Gynecology, Cheil General Hospital \& Women's Healthcare Center,

Dankook University College of Medicine, Seoul, Gyeonggi-do 04619;

${ }^{2}$ Department of Obstetrics and Gynecology, Korea University Guro Hospital, Seoul, Gyeonggi-do 08308;

${ }^{3}$ Department of Obstetrics and Gynecology, Korea University Anam Hospital, Seoul 02841;

${ }^{4}$ Department of Obstetrics and Gynecology, Korea University Ansan Hospital, Gyeonggi-do 15355;

${ }^{5}$ Department of Obstetrics and Gynecology, Kyung Hee University, School of Medicine, Seoul, Gyeonggi-do 05278;

${ }^{6}$ Department of Obstetrics and Gynecology, Pusan National University Yangsan Hospital, Yangsan, Gyeongsangnam-do 50612;

${ }^{7}$ Department of Obstetrics and Gynecology, Gil Medical Center, Gachon University, Namdong-gu, Incheon 21565;

${ }^{8}$ Department of Obstetrics and Gynecology, Konyang University Hospital, Konyang University College of Medicine,

Daejeon 35365; ${ }^{9}$ Department of Obstetrics and Gynecology, Hanyang University Guri Hospital,

Guri-si, Gyeonggi-do 11923, Republic of Korea

Received January 28, 2015; Accepted March 15, 2016

DOI: $10.3892 /$ etm.2016.3600

\begin{abstract}
The present study focused on the degree of tissue injury following single-port laparoscopic surgery (SPLS) and multiport laparoscopic surgery (MPLS) for the treatment of various benign gynecologic diseases. A total of 228 patients were prospectively enrolled at seven academic centers in South Korea between April 2011 and September 2012. Of these, 122 patients underwent SPLS and 106 patients underwent MPLS. The serum levels of C-reactive protein, creatine phosphokinase, lactic dehydrogenase and cancer antigen 125 were measured preoperatively and on postoperative day 4 by immunonephelometry. Cosmetic satisfaction and postoperative pain scores (visual analogue scale) were analyzed. Postoperative changes in the levels of the serum markers were found to be similar between the SPLS and MPLS groups. However, the postoperative pain scores at $48 \mathrm{~h}$ were significantly lower in the SPLS group when compared with those in the MPLS $(\mathrm{P}=0.001)$. In addition, patient-controlled analgesia was used more frequently by patients in the MPLS
\end{abstract}

\footnotetext{
Correspondence to: Dr Un Suk Jung, Department of Obstetrics and Gynecology, Hanyang University Guri Hospital, Gyeongchun-ro 153, Guri-si, Gyeonggi-do 11923, Republic of Korea

E-mail: petrow@naver.com
}

Key words: tissue injuries, single-port laparoscopy, benign gynecologic disease group ( $\mathrm{P}=0.003)$. The present study is the first prospective investigation of tissue injury resulting from SPLS and MPLS in gynecology. In conclusion, the current study demonstrated that serum marker levels during SPLS were similar to those during MPLS in the treatment of benign gynecologic diseases. However, SPLS is a reasonable alternative to MPLS and is associated with comparable tissue injury, improved cosmesis and reduced postoperative pain.

\section{Introduction}

Gynecological laparoscopic surgery has replaced laparotomy for the treatment of benign diseases, including uterine fibroids and adnexal cysts, since it has various advantages, including a shorter hospital stay, decreased postoperative pain, a lower wound infection rate and improved cosmesis (1). The use of single-incision laparoscopy in gynecology was first described in the study by Wheeless in 1969 (2). Single-port laparoscopic surgery (SPLS) is a less invasive surgical procedure when compared with conventional multiport laparoscopic surgery (MPLS) (3).

The outcome of SPLS is commonly evaluated on the basis of morbidity, pain, recovery and cosmesis. In a previous randomized study, no differences were identified in the operative time, intraoperative or immediate postoperative complications, estimated blood loss, shoulder tip pain, time to first flatus or length of hospital stay between single-port laparoscopic-assisted vaginal hysterectomy and conventional multiport laparoscopic-assisted vaginal hysterectomy (4). However, postoperative pain and use of analgesics were significantly reduced in the single-port group compared with 
the conventional multiport group (4). However, a further randomized study found similar levels of postoperative pain and significantly increased shoulder tip pain in women who had undergone laparoendoscopic single-site surgery compared with those who had undergone conventional laparoscopic surgery (3). These conflicting results may result from subjective assessment of the pain levels by patients.

Therefore, the use of a more objective method is required to compare the effects of the two operative methods. One of the objective means consists of evaluating the degree of differences of surgical tissue injuries. The degree of tissue injury can be assessed by measuring the serum levels of specific proteins and enzymes associated with tissue injuries, including $\mathrm{C}$-reactive protein (CRP), creatine phosphokinase (CPK), lactate dehydrogenase $(\mathrm{LDH})$ and cancer antigen 125 (CA-125) (5,6). Since surgical injuries stimulate a tissue response during surgical procedures, the serum marker levels also increase in these patients (7). The measurement of serum marker levels thus offers an objective method for the determination of the relative invasiveness of the procedures (8-11).

The present study focused on the degree of tissue injury following SPLS and MPLS. A previous gynecologic study noted more marked intraperitoneal injuries following laparotomy rather than following laparoscopy (12). However, to the best of our knowledge, no previous study has examined the difference in tissue injuries between SPLS and MPLS. Therefore, we report the first multicenter prospective study that compares the degree of tissue injury between the two laparoscopic techniques.

\section{Patients and methods}

Patients. A total of 228 patients (median age, 43 years; age range, 12-79 years) with operative indications for benign gynecologic disease were prospectively enrolled at seven academic centers (Korea University Guro Hospital, Seoul; Korea University Anam Hospital, Seoul; Korea University Ansan Hospital, Ansan; Kyung Hee University, School of Medicine, Seoul; Pusan National University Yangsan Hospital, Yangsan; Gil Medical Center, Gachon University, Incheon; Konyang University Hospital, Daejeon) in South Korea between April 2011 and September 2012. Exclusion criteria included the following: Previous low midline abdominal surgery; body mass index of $>30 \mathrm{~kg} / \mathrm{m}^{2}$; uterine myoma of $>8 \mathrm{~cm}$ detected by transvaginal ultrasonography; severe adhesions or endometriosis; American Society of Anesthesiologists grade III or higher (13); and any other contraindication for laparoscopic surgery.

The patients were preoperatively diagnosed with uterine fibroid, adenomyosis, cervical dysplasia, ovarian cyst and tubal pregnancy. After informing the patients of the advantages, disadvantages and limitations of SPLS and MPLS, one of these procedures was selected by each participant and was performed with their consent. Approval from the Institutional Review Board was obtained at each clinical center, and all patients provided written informed consent for participation in the present study.

Surgeries. All patients were admitted to hospital, preoperatively prepared for surgery, including the administration of an enema the night before and $>8 \mathrm{~h}$ fasting. The procedure was performed under general anesthesia with the patients in the dorsal litothomy position (14). A prophylactic antibiotic (single dose of the first-generation cephalosporin; Dong-A Pharm, Seoul, Korea) was administered prior to the surgery. During the laparoscopic surgeries, a $\mathrm{CO}_{2}$ pneumoperitoneum was constructed to maintain the intraabdominal pressure at 10-12 mmHg. During SPLS, a single intraumbilical incision approximately $2 \mathrm{~cm}$ in length was made using an Octo-Port (DalimSurgNet, Seoul, Korea). During MPLS, four incision sites (one 12-mm intraumbilical port and three 5-mm ports) were used along with trocars according to surgeon preference. Experienced surgeons performed these procedures, after performing at least 30 MPLS and 20 SPLS and participating in a workshop to ensure standardization of the surgical procedures.

Assessment of postoperative tissue injuries. The serum levels of CRP, CPK, LDH, and CA-125 were measured to assess the impact of two operative techniques on tissue injury. Briefly, blood samples $(20 \mathrm{ml})$ from a peripheral vein puncture were collected preoperatively and on postoperative day 4. Each blood sample was centrifuged at 2,191 x g for $10 \mathrm{~min}$, and the collected serum was stored at $-70^{\circ} \mathrm{C}$ in individual tubes. Serum CRP level was measured by rate immunonephelometry (cat. no. OSR 6147/AU; Beckman Coulter, Inc., Brea, CA, USA) using commercial kits. CPK and LDH were measured using a kinetic ultraviolet method (cat. no. 89137-236; Olympus Diagnostica GmbH, Hamburg, Germany). CA-125 was determined using a radioimmunoassay kit (cat. no. M2233-B64312/IRMA; Centocor Diagnostics, Inc., Malvern, UK). The assays were performed according to the manufacturer's instructions. All samples were analyzed at a single institution (Korea University Guro Hospital).

The operative time was calculated from the first skin incision to the skin closure. The estimated blood loss was calculated by the difference in the total quantity of suctioned and irrigation fluids. In addition, hemoglobin levels were evaluated on the preoperative and postoperative day 4 . Patients were allowed to leave the hospital after day 2. The use of additional ports, conversion to open laparotomy and postoperative complications were also analyzed. Patient satisfaction with cosmesis was assessed using the scar satisfaction score (range, $0-5 ; 5=$ very satisfactory) that was calculated at 4 days, 4 weeks and 8 weeks after surgery. Postoperative pain was controlled by patient-controlled analgesia (PCA). Participants received parenteral non-steroidal anti-inflammatory drugs (ketorolac tromethamine, $30 \mathrm{mg}$; intramuscular injection; Yuhan Co., Seoul, Korea) on demand for additional pain control. Postoperative pain was assessed using a visual analogue scale (VAS) score (range, $0-10 ; 10=$ severe pain) at 4, 24 and $48 \mathrm{~h}$.

Statistical analysis. For statistical analysis of the variables between the two laparoscopic groups, changes in continuous comparative data (such as biochemical markers) were analyzed using the Student's t-test. The $\chi^{2}$ test was used to compare the proportions between the groups. Values of $\mathrm{P}<0.05$ were considered as statistically significant. The statistical software IBM SPSS statistics version 20.0 (IBM Corp., Armonk, NY, USA) was used for all the data analyses. 


\section{Results}

Patient characteristics. A total of 228 patients were recruited into the study, of which 122 underwent SPLS and 106 underwent MPLS. There were no statistically significant differences in the mean age, mean body mass index (BMI) or previous abdominal surgery between the groups (Table I). Laparoscopic surgery was indicated in 122 cases of uterine disease (including fibroids, adenomyosis, preinvasive cervical neoplasia and endometrial hyperplasia) and 106 cases of adnexal disease (including ovarian cystadenoma, dermoid cyst, fibroma and tubal pregnancy), as shown in Table II. Patients with uterine disease more commonly underwent MPLS (66\%) compared with SPLS (34\%), whereas patients with adnexal disease more commonly underwent SPLS (58.2\%) rather than MPLS $(41.8 \%$; $\mathrm{P}<0.001)$.

Surgical findings. The operative results are summarized in Table III. Patients in the SPLS group experienced slightly shorter surgery duration compared with that in the MPLS group, however, this difference was not statistically significant $(85.9 \pm 53.5$ vs. $95.9 \pm 71.4 \mathrm{~min}$, respectively; $\mathrm{P}=0.239)$. In addition, no significant difference was observed in the estimated blood loss or the preoperative and postoperative hemoglobin levels between the SPLS and MPLS groups. Furthermore, no postoperative complications occurred in the two groups. However, two patients in the MPLS group underwent conversion to the laparotomy approach during the MPLS surgery.

Postoperative clinical outcomes. Postoperative pain scores were compared between the two groups (Table IV). The postoperative VAS pain scores at $4 \mathrm{~h}(\mathrm{P}=0.208)$ and $24 \mathrm{~h}$ $(\mathrm{P}=0.613)$ did not differ between the SPLS and MPLS groups. By contrast, the postoperative VAS pain scores at $48 \mathrm{~h}$ were significantly lower in the SPLS group when compared with those in the MPLS group $(2.2 \pm 1.1$ vs. $2.7 \pm 1.0$, respectively; $\mathrm{P}=0.001)$. In addition, PCA was more frequently used by the patients in the MPLS group $(\mathrm{P}=0.003)$ compared with those in the SPLS group. Total nonsteroidal anti-inflammatory drug requirements were similar between the two groups $(\mathrm{P}=0.244)$.

Patients in the SPLS were significantly more satisfied with the postoperative cosmetic results (Table IV). Scar satisfaction scores at 4 days were significantly greater in the SPLS group when compared with the MPLS group $(\mathrm{P}<0.001)$, and persisted at 4 and 8 weeks after surgery $(\mathrm{P}=0.003$ and $\mathrm{P}=0.030$, respectively). The time from surgery to return to work was also shorter in the SPLS group compared with that in the MPLS group (8.2 vs. 10.8 days; $\mathrm{P}=0.008)$.

Serum levels of tissue injury markers. With regard to the serum levels of tissue injury markers, similar preoperative values were observed between the two groups (Table V). Compared with the preoperative values, postoperative CRP level at day 4 was significantly increased in the SPLS $(0.4 \pm 0.9$ vs. $10.9 \pm 18.4 \mathrm{mg} / 1$, respectively; $\mathrm{P}<0.001)$ and MPLS groups $(0.4 \pm 0.8$ vs. $8.6 \pm 18.1$, respectively; $\mathrm{P}<0.001)$. Preoperative and postoperative changes in CA-125, CPK, and LDH levels were not significantly different between the two groups, with the exception of CA-125 that was significantly increased in the SPLS group at postoperative day $4(23.5 \pm 21$ vs. $29.3 \pm 17.1 .6 \mathrm{U} / \mathrm{ml} ; \mathrm{P}=0.028)$. However, no statistically significant variations were observed between the SPLS and MPLS groups, as shown in Table VI and Fig. 1. Furthermore, changes in the preoperative and postoperative (day 4) CRP levels were similar in the SPLS $(0.4 \pm 0.9$ vs. $0.4 \pm 0.8 \mathrm{mg} / 1$, respectively; $\mathrm{P}=0.950)$ and MPLS (10.5 \pm 18.0 vs. $8.4 \pm 17.5 \mathrm{mg} / 1$, respectively; $\mathrm{P}=0.950)$ groups.

\section{Discussion}

Laparoscopic surgery has established advantages in the treatment of benign gynecologic diseases $(1,15)$. Numerous surgeons have attempted to decrease the size and number of ports to maintain the surgery minimally invasive (16). Recent advances in laparoscopic equipment and improvements in surgical skills have resulted in the challenge of performing a single abdominal incision in gynecologic surgery (17). The present study evaluated the surgical injuries induced by two different laparoscopic procedures (single-port and multiport surgery) for the treatment of various benign gynecologic diseases. The results showed no statistically significant differences in the serum levels of tissue injury markers between the SPLS and MPLS groups. Patient satisfaction of the cosmetic results and the postoperative VAS pain scores were found to be improved in the SPLS group compared with those in the MPLS group.

Tissue injuries during surgery produce a generalized inflammatory, immunosuppressive and metabolic reaction $(18,19)$. CRP, CPK, LDH and CA-125 are well known indicators of tissue injury, since their levels increase as a result of major surgery. In the present study, a significant increase was observed in the serum levels of CRP (in both groups) and CA-125 (only in the SPLS group) following laparoscopic surgery. Increases in serum CPK and LDH levels subsequent to surgery may also depend on and reflect injury severity (5). However, the current study results showed no concomitant increases in the serum levels of CPK and LDH on postoperative day 4 . This may be due to a decrease in serum peak levels by clearence. A previous study revealed that the serum levels of CPK and LDH peak at $30 \mathrm{~h}$ and $34 \mathrm{~h}$, respectively, after an incision (5).

Several studies are investigating tissue injury following laparoscopic surgery (20-22). One such study comparing serum levels of tissue injury markers in abdominal and laparoscopic-assisted hysterectomy reported that the laparoscopic group had lower postoperative CRP and CPK values on postoperative days 1 and 2 (21). A more recent study of laparoscopic hepatectomy found that SPLS and MPLS had comparable impacts on the patients' stress responses (22). However, no significant differences in serum marker levels were identified between the SPLS and MPLS groups in the current study. According to the results, the number of trocar incisions has little impact on tissue injuries.

Furthermore, the present study found that women in the SPLS group had a lower pain level $48 \mathrm{~h}$ after surgery and used reduced PCA when compared with women in the MPLS group. Pain VAS scores were similar up to $24 \mathrm{~h}$ after surgery; however, these were significantly different at 
Table I. Patient characteristics.

\begin{tabular}{lccr}
\hline Parameter & SPLS $(\mathrm{n}=122)$ & MPLS $(\mathrm{n}=106)$ & P-value \\
\hline Mean age (years) & $41.5 \pm 12.8$ & $44.5 \pm 10.6$ & 0.055 \\
Mean body-mass index $\left(\mathrm{kg} / \mathrm{m}^{2}\right)$ & $23.2 \pm 3.1$ & $23.5 \pm 2.8$ & 0.395 \\
Previous abdominal surgery & $58(47.5 \%)$ & $49(46.2 \%)$ & 0.894
\end{tabular}

SPLS, single-port laparoscopic surgery; MPLS, multiport laparoscopic surgery.

Table II. Surgical indication.

\begin{tabular}{lcc}
\hline Disease type & SPLS $(\mathrm{n}=122)$ & MPLS (n=106) \\
\hline Uterine disease & $51(41.8 \%)$ & $70(66.0 \%)$ \\
Fibroid and adenomyosis & 50 & 66 \\
Endometrial hyperplasia & 1 & 1 \\
Preinvasive cervical neoplasia & 0 & 3 \\
Adnexal disease & $71(58.2 \%)$ & $36(34.0 \%)$ \\
Cystadenoma & 45 & 31 \\
Dermoid cyst & 12 & 3 \\
Fibroma & 3 & 0 \\
Tubal pregnancy & 11 & 2 \\
\hline
\end{tabular}

$\mathrm{P}<0.001$. SPLS, single-port laparoscopic surgery; MPLS, multiport laparoscopic surgery.

Table III. Surgical results.

\begin{tabular}{|c|c|c|c|}
\hline Parameter & SPLS $(n=122)$ & MPLS (n=106) & P-value \\
\hline Duration of surgery (min) & $85.9 \pm 53.5$ & $95.9 \pm 71.4$ & $0.239^{c}$ \\
\hline Estimated blood loss (ml) & $132.9 \pm 233.9$ & $142.0 \pm 176.0$ & $0.740^{\mathrm{c}}$ \\
\hline \multicolumn{4}{|l|}{ Hemoglobin (g/dl) } \\
\hline Preoperative day & $12.3 \pm 1.9$ & $12.1 \pm 1.6$ & $0.485^{\mathrm{c}}$ \\
\hline Postoperative day 4 & $10.4 \pm 1.7$ & $11.3 \pm 8.8$ & $0.259^{c}$ \\
\hline Operation type & & & $<0.001^{\mathrm{d}}$ \\
\hline Adnexa surgery ${ }^{\mathrm{a}}$ & 70 & 34 & \\
\hline Hysterectomy $^{\mathrm{b}}$ & 50 & 57 & \\
\hline Myomectomy & 2 & 15 & \\
\hline Conversion to laparotomy & 0 & 2 & $0.215^{\mathrm{e}}$ \\
\hline Postoperative complication & 0 & 0 & $>0.999$ \\
\hline
\end{tabular}

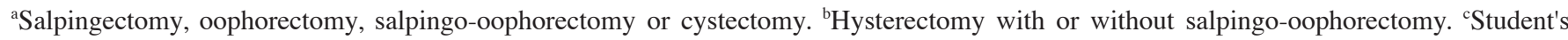
t-test; ' $\chi^{2}$ test; ${ }^{\mathrm{e} F i s h e r ' s ~ e x a c t ~ t e s t . ~ S P L S, ~ s i n g l e-p o r t ~ l a p a r o s c o p i c ~ s u r g e r y ; ~ M P L S, ~ m u l t i p o r t ~ l a p a r o s c o p i c ~ s u r g e r y . ~}$

$48 \mathrm{~h}$ after surgery, with lower pain scores observed in the SPLS group. Late postoperative pain may mainly reflect ambulation-induced pain from the abdominal wounds. Shorter skin incision and fewer muscle components in the umbilical area can minimize postoperative pain in SPLS, as previously reported (23). Several studies on gynecologic benign diseases have shown reduced postoperative pain and improved cosmetic outcomes subsequent to SPLS (24-26).
Other potential benefits of SPLS include a shorter recovery period, lower morbidity rates and reduced costs (27). The mean time until return to work and scar satisfaction score were significantly improved in the SPLS group when compared with the MPLS group in the current study.

The present study is the first prospective, multicenter, case-control study on tissue injury resulting from SPLS and MPLS in gynecologic surgery, while an advantage of the 
Table IV. Postoperative clinical outcomes.

\begin{tabular}{|c|c|c|c|}
\hline Parameter & SPLS $(n=122)$ & MPLS (n=106) & P-value \\
\hline \multicolumn{4}{|l|}{ Pain profile (VAS score) ${ }^{\mathrm{a}}$} \\
\hline At $4 \mathrm{~h}$ & $5.0 \pm 2.1$ & $4.5 \pm 2.4$ & 0.208 \\
\hline At $24 \mathrm{~h}$ & $3.5 \pm 1.5$ & $3.6 \pm 1.6$ & 0.613 \\
\hline At $48 \mathrm{~h}$ & $2.2 \pm 1.1$ & $2.7 \pm 1.0$ & 0.001 \\
\hline \multicolumn{4}{|l|}{ Analgesia requirement ${ }^{\mathrm{b}}$} \\
\hline PCA & $110(98.2 \%)$ & $105(99.1 \%)$ & 0.003 \\
\hline NSAID & $36(29.5 \%)$ & $26(24.5 \%)$ & 0.244 \\
\hline \multicolumn{4}{|l|}{ Scar satisfaction score ${ }^{a}$} \\
\hline At 4 days & $4.2 \pm 0.8$ & $3.8 \pm 0.8$ & $<0.001$ \\
\hline At 4 weeks & $4.5 \pm 0.6$ & $4.3 \pm 0.7$ & 0.003 \\
\hline At 8 weeks & $4.8 \pm 0.5$ & $4.6 \pm 0.6$ & 0.030 \\
\hline Time until return to work (days) ${ }^{\mathrm{a}}$ & $8.2 \pm 6.5$ & $10.8 \pm 8.0$ & 0.008 \\
\hline
\end{tabular}

Data are presented as the ${ }^{a}$ mean \pm standard deviation or ${ }^{b} \mathrm{n}(\%)$. SPLS, single-port laparoscopic surgery; MPLS, multiport laparoscopic surgery; VAS, visual analogue scale; PCA, patient-controlled analgesia; NSAID, nonsteroidal anti-inflammatory drug.

Table V. Serum tissue injury markers.

\begin{tabular}{lccc}
\hline Surgery type & Preoperative day & Postoperative day 4 & P-value \\
\hline Single-port laparoscopy & & & \\
CRP (mg/l) & $0.4 \pm 0.90$ & $10.9 \pm 18.4$ & 0.001 \\
CPK (U/l) & $74.3 \pm 38.2$ & $64.1 \pm 53.2$ & 0.534 \\
LDH (U/l) & $416.5 \pm 174.0$ & $401.7 \pm 158.5$ & 0.028 \\
CA-125 (U/ml) & $23.5 \pm 21.6$ & & \\
Multiport laparoscopy & & $8.6 \pm 18.1$ & \\
CRP (mg/l) & $0.4 \pm 0.8$ & $73.7 \pm 81.9$ & 0.1 \\
CPK (U/l) & $73.7 \pm 52.6$ & $360.1 \pm 137.8$ & 0.997 \\
LDH (U/l) & $373.6 \pm 121.1$ & $26.1 \pm 27.2$ & 0.493 \\
CA-125 (U/ml) & $22.7 \pm 19.8$ & 0.315 \\
\hline
\end{tabular}

CRP, C-reactive protein; CPK, creatine phosphokinase; LDH, lactate dehydrogenase; CA-125, cancer antigen 125.

Table VI. Serum tissue injury markers.

\begin{tabular}{|c|c|c|c|c|c|c|}
\hline \multirow{2}{*}{$\begin{array}{l}\text { Serum } \\
\text { marker }\end{array}$} & \multicolumn{3}{|c|}{ Preoperative day } & \multicolumn{3}{|c|}{ Postoperative day 4} \\
\hline & SPLS & MPLS & P-value & SPLS & MPLS & P-value \\
\hline CRP (mg/l) & $0.4 \pm 0.9$ & $0.4 \pm 0.8$ & 0.950 & $10.5 \pm 18.0$ & $8.4 \pm 17.5$ & 0.373 \\
\hline CPK (U/l) & $74.3 \pm 38.2$ & $73.8 \pm 52.6$ & 0.929 & $64.1 \pm 53.2$ & $73.7 \pm 81.9$ & 0.313 \\
\hline LDH (U/1) & $416.5 \pm 174.0$ & $373.6 \pm 121.1$ & 0.051 & $401.7 \pm 158.5$ & $360.1 \pm 137.8$ & 0.060 \\
\hline CA-125 (U/ml) & $23.5 \pm 21.6$ & $22.7 \pm 19.8$ & 0.789 & $34.2 \pm 34.9$ & $26.4 \pm 27.2$ & 0.071 \\
\hline
\end{tabular}

SPLS, single-port laparoscopic surgery; MPLS, multiport laparoscopic surgery; CRP, C-reactive protein; CPK, creatine phosphokinase; LDH, lactate dehydrogenase; CA-125, cancer antigen 125.

study is the a relatively large number of patients enrolled. In conclusion, the current study demonstrated that serum levels of tissue injury markers during SPLS were similar to those during MPLS, performed for the treatment of benign gynecologic diseases. Although the present study failed to demonstrate the superiority of SPLS over MPLS according 
A

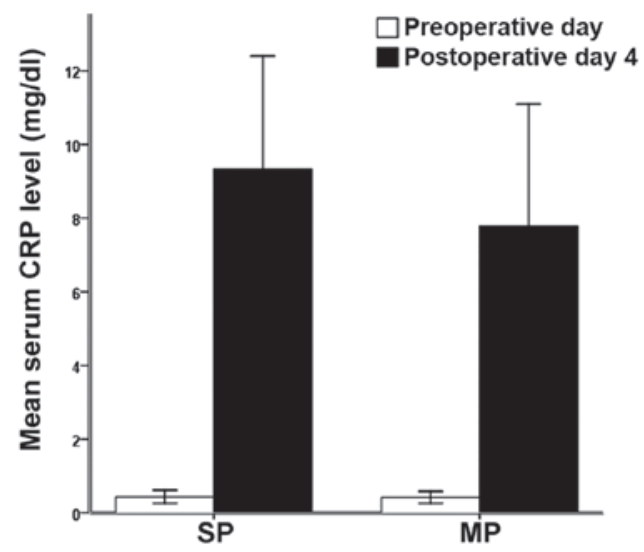

C

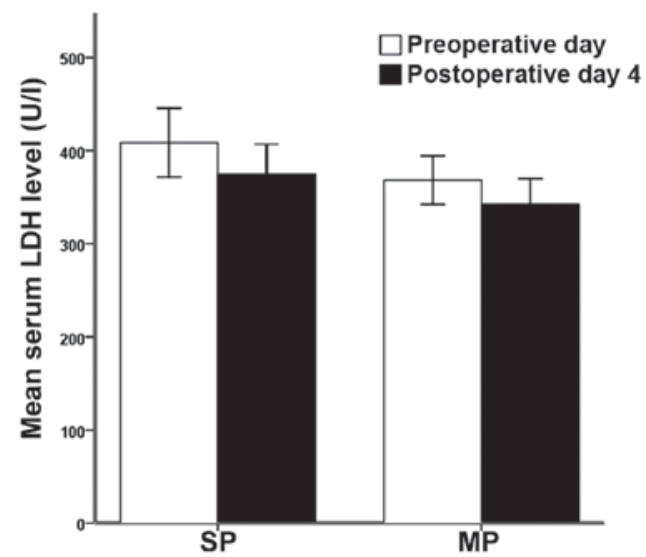

B

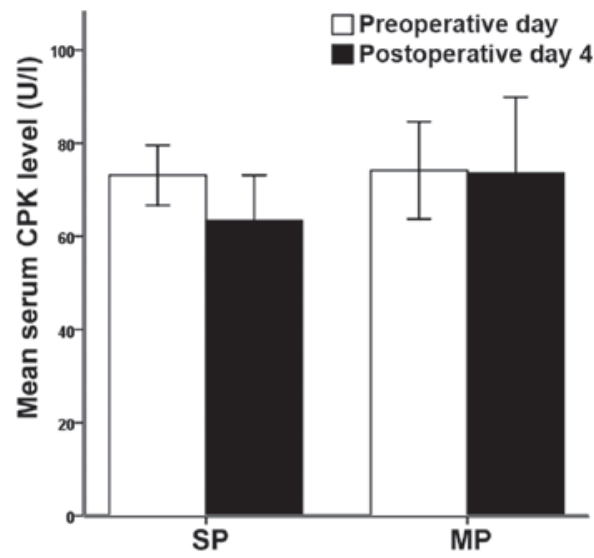

D

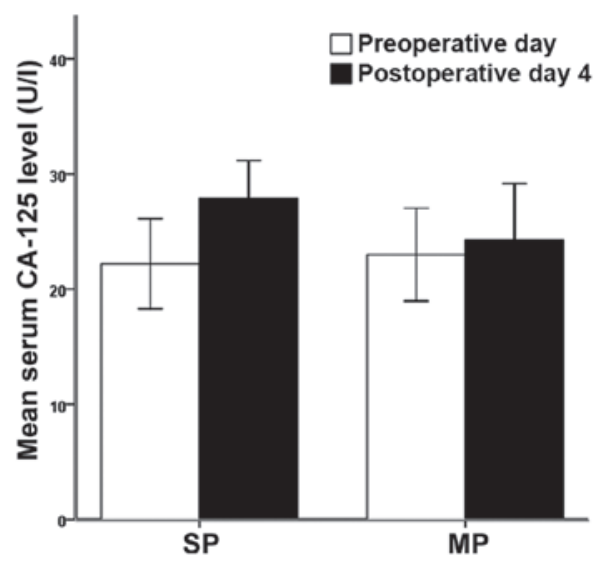

Figure 1. Serum levels of tissue injury markers. Postoperative changes in (A) CRP, (B) CPK, (C) LDH and (D) CA-125 levels were not significantly different between the SP and MP groups. Data are presented as the mean \pm standard deviation. SP, single-port laparoscopy; MP, multiport laparoscopy; CRP, C-reactive protein; CPK, creatine phosphokinase; LDH, lactate dehydrogenase; CA-125, cancer antigen 125.

to the serum marker levels, SPLS in gynecology is considered as a reasonable alternative to MPLS and is associated with comparable tissue injuries, improved cosmesis, reduced postoperative pain and a shorter recovery period.

\section{References}

1. Nieboer TE, Johnson N, Lethaby A, Tavender E, Curr E, Garry R, van Voorst S, Mol BW and Kluivers KB: Surgical approach to hysterectomy for benign gynaecological disease. Cochrane Database Syst Rev: CD003677, 2009.

2. Wheeless CR: A rapid, inexpensive and effective method of surgical sterilization by laparoscopy. J Reprod Med 3: 65-69, 1969.

3. Hoyer-Sørensen C, Vistad I and Ballard K: Is single-port laparoscopy for benign adnexal disease less painful than conventional laparoscopy? A single-center randomized controlled trial. Fertil Steril 98: 973-979, 2012

4. Chen YJ, Wang PH, Ocampo EJ, Twu NF, Yen MS and Chao KC: Single-port compared with conventional laparoscopic-assisted vaginal hysterectomy: A randomized controlled trial. Obstet Gynecol 117: 906-912, 2011.

5. Tabatabai M, Segal R, Amidi M, Stremple JF, Caines M and Kirimli B: Serum creatine phosphokinase, lactic dehydrogenase and their isoenzymes in the perioperative period. J Clin Anesth 1: 277-283, 1989.

6. Härkki-Sirén P, Sjöberg J, Toivonen J and Tiitinen A: Clinical outcome and tissue trauma after laparoscopic and abdominal hysterectomy: A randomized controlled study. Acta Obstet Gynecol Scand 79: 866-871, 2000.

7. Holub Z, Jabor A, Fischlova D, Palasek V and Shomani A: Evaluation of perioperative stress after laparoscopic and abdominal hysterectomy in premalignant and malignant disease of the uterine cervix and corpus. Clin Exp Obstet Gynecol 26: 12-15, 1999.
8. Bergin PF, Doppelt JD, Kephart CJ, Benke MT, Graeter JH, Holmes AS, Haleem-Smith H, Tuan RS and Unger AS: Comparison of minimally invasive direct anterior versus posterior total hip arthroplasty based on inflammation and muscle damage markers. J Bone Joint Surg Am 93: 1392-1398, 2011.

9. Grande M, Tucci GF, Adorisio O, Barini A, Rulli F, Neri A, Franchi F and Farinon AM: Systemic acute-phase response after laparoscopic and open cholecystectomy. Surg Endosc 16: 313-316, 2002.

10. Suter M, Martinet O and Spertini F: Reduced acute phase response after laparoscopic total extraperitoneal bilateral hernia repair compared to open repair with the Stoppa procedure. Surg Endosc 16: 1214-1219, 2002.

11. Malik E, Buchweitz O, Müller-Steinhardt M, Kressin P, Meyhöfer-Malik A and Diedrich K: Prospective evaluation of the systemic immune response following abdominal, vaginal, and laparoscopically assisted vaginal hysterectomy. Surg Endosc 15: 463-466, 2001.

12. Volz J, Köster S and Leweling H: Surgical trauma and metabolic changes induced by surgical laparoscopy versus laparotomy. Gynaecol Endosc 6: 1-6, 1997.

13. Dripps RD: New classification of physical status. Anesthesiol 24: 111, 1963.

14. Jung YW, Lee M, Yim GW, Lee SH, Paek JH, Kwon HY, Nam EJ, Kim SW and Kim YT: A randomized prospective study of single-port and four-port approaches for hysterectomy in terms of postoperative pain. Surg Endosc 25: 2462-2469, 2011.

15. Walsh CA, Walsh SR, Tang TY and Slack M: Total abdominal hysterectomy versus total laparoscopic hysterectomy for benign disease: A meta-analysis. Eur J Obstet Gynecol Reprod Biol 144: 3-7, 2009.

16. Lee M, Nam EJ, Kim S, Kim JH, Kim YT and Kim SW: Two-port access laparoscopic surgery in gynecologic oncology. Int J Gynecol Cancer 23: 935-942, 2013. 
17. Escobar PF, Fader AN, Paraiso MF, Kaouk JH and Falcone T: Robotic-assisted laparoendoscopic single-site surgery in gynecology: Iinitial report and technique. J Minim Invasive Gynecol 16: 589-591, 2009.

18. Baigrie RJ, Lamont PM, Kwiatkowski D, Dallman MJ and Morris PJ: Systemic cytokine response after major surgery. $\mathrm{Br}$ J Surg 79: 757-760, 1992.

19. Uzunköy A, Coskun A, Akinci OF and Kocyigit A: Systemic stress responses after laparoscopic or open hernia repair. Eur J Surg 166: 467-471, 2000.

20. Ueda K, Turner P and Gagner M: Stress response to laparoscopic liver resection. HPB (Oxford) 6: 247-252, 2004.

21. Atabekoglu C, Sönmezer M, Güngör M, Aytaç R, Ortaç F and Unlü C: Tissue trauma in abdominal and laparoscopic-assisted vaginal hysterectomy. J Am Assoc Gynecol Laparosc 11: 467-472, 2004

22. Qin M, Zou F, Zheng M and Zhao H: Systemic stress responses after laparoendoscopic single-site hepatectomy: A perspective controlled study. Hepatogastroenterology 59: 1204-1207, 2012 .
23. Ghezzi F, Cromi A, Colombo G, Uccella S, Bergamini V, Serati M and Bolis P: Minimizing ancillary ports size in gynecologic laparoscopy: A randomized trial. J Minim Invasive Gynecol 12: 480-485, 2005.

24. Yoo EH and Shim E: Single-port access compared with three-port laparoscopic adnexal surgery in a randomized controlled trial. J Int Med Res 41: 673-680, 2013.

25. Park JY, Kim TJ, Kang HJ, Lee YY, Choi CH, Lee JW, Bae DS and Kim BG: Laparoendoscopic single site (LESS) surgery in benign gynecology: Perioperative and late complications of 515 cases. Eur J Obstet Gynecol Reprod Bio 167: 215-218, 2013.

26. Yim GW, Jung YW, Paek J, Lee SH, Kwon HY, Nam EJ, Kim S, Kim JH, Kim YT and Kim SW: Transumbilical single-port access versus conventional total laparoscopic hysterectomy: Surgical outcomes. Am J Obstet Gynecol 203: 26.e1-a6, 2010.

27. Jung YW, Kim YT, Lee DW, Hwang YI, Nam EJ, Kim JH and Kim SW: The feasibility of scarless single-port transumbilical total laparoscopic hysterectomy: Initial clinical experience. Surg Endosc 24: 1686-1692, 2010. 